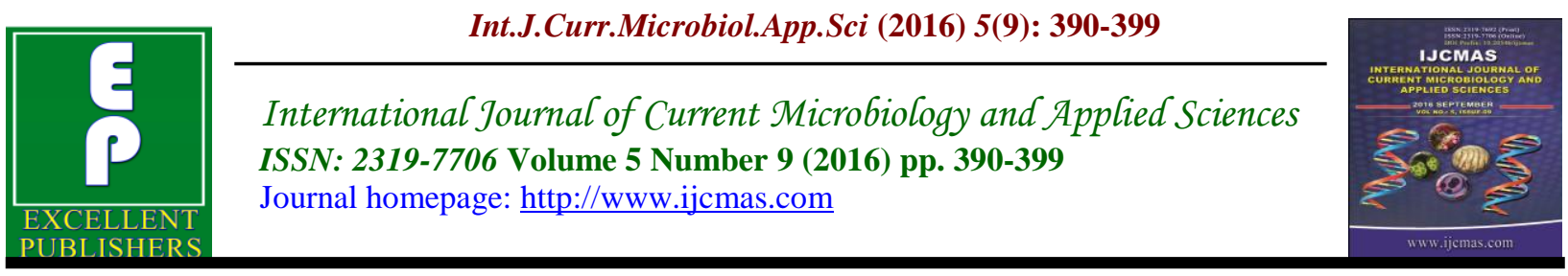

Original Research Article

http://dx.doi.org/10.20546/ijcmas.2016.509.042

\title{
Multidrug Resistant Proteus mirabilis Isolated from Urinary Tract Infection from Different Hospitals in Baghdad City
}

\author{
Essam F.A. Al-Jumaily* and Sara Hussein Zgaer \\ Biotechnology Department, Genetic Engineering and Biotechnology Institute for Postgraduate \\ studies, Baghdad University, Baghdad, Iraq \\ *Corresponding author
}

\begin{tabular}{|c|c|}
\hline & A B S T R A C T \\
\hline $\begin{array}{l}\text { Ke y w o r d s } \\
\text { Proteus mirabilis; } \\
\text { urinary tract } \\
\text { infection; } \\
\text { antimicrobial } \\
\text { resistant. }\end{array}$ & $\begin{array}{l}\text { Clinical one hundred thirty two samples were collected during the time from } \\
13 / 9 / 2015 \text { to } 12 / 11 / 2015 \text { of urine samples from patients suffering from urinary tract } \\
\text { infection (UTI), from different hospitals in Baghdad city. The results of cultural, } \\
\text { microscopic, biochemical tests, which was confirmed by API } 20 \text { E indicated that in } \\
\text { urine samples Escherichia coli have the highest occurrence frequency followed by } \\
\text { Proteus mirabilis and Klebsiella species. Susceptibility test against twelve } \\
\text { antimicrobial agents was done for all of the Proteus mirabilis pathogenic isolates }\end{array}$ \\
\hline Article Info & $\begin{array}{l}\text { (53 1solates). The results displayed that most of the isolates were resistant to } \\
\text { Methicillin, methoprim and Rifampin followed by trimethoprim-sulfamethoxazole, }\end{array}$ \\
\hline $\begin{array}{l}\text { Accepted: } \\
15 \text { August } 2016 \\
\text { Available Online: } \\
10 \text { September } 2016\end{array}$ & $\begin{array}{l}\text { chloramphenicol, and cefazoline, while the most effective antimicrobial agents } \\
\text { against } P \text {. mirabilis were Imipenem, Amikacin, Azetronam, Azithromycin, } \\
\text { Ciprofloxacin, whereas a moderate affect appeared against both gentamycin and } \\
\text { tobramycin. }\end{array}$ \\
\hline
\end{tabular}

\section{Introduction}

The urinary tract infection (UTI) is defined as infection or colonization of the urinary tract (urethra, bladder, ureter and kidney) by microorganisms. The most common bacterial uropathogens in UTI are: Escherichia coli, Proteus mirabilis, Pseudomonas aeruginosa, Klebsiella pneumoniae, Staphylococcus saprophyticus, Enterococcus faecalis and Enterobacter cloacae (Foxman, 2014).

A Urinary tract infection can occur anywhere along the Urinary tract. It includes urethritis, cystitis, pyelonephritis, epidydimitis, prostatitis, perinephritis, and abscess and considered one among the most common infectious diseases is widely seen among all age groups of individuals. However some groups of people are more prone to UTI than others. For example there is a higher risk to develop UTI in diabetic patients (Chen et al., 2009). Females have fourteen times more chance to develop UTI than men.The differences are attributed to involvement of several factors. Such as they has a shorter urethra compare to men which open nearer to the anus so that the lower third of urethra is continually contaminated 
with pathogens from vagina and rectum. Women tend not to empty their bladder as completely as men (Minardi, 2011).

Proteus mirabilis is a Gram-negative bacterium which is well-known for its ability to robustly swarm across surfaces in a striking bulls'-eye pattern. Clinically, this organism is most frequently a pathogen of the urinary tract, particularly in patients undergoing long-term catheterization. $P$. mirabilis uses a diverse set of virulence factors to access and colonize the host urinary tract, including urease and stone formation, fimbriae and other adhesins, iron and zinc acquisition, proteases and toxins such hemolysin and its function of pore formation, biofilm formation, and regulation of pathogenesis (Schaffer et al., 2016). The routine use of antibiotics leads to the prevalence of antibiotic resistance and development of antibiotic resistance genes particularly, within gram negative organisms and this consider as the most serious problems in the field of medicine (Sedláková et al., 2014). In P.mirabilis the antimicrobial resistance is increasing, such as the resistance to extended-spectrum cephalosporin's due to the production of extended-spectrum $\beta$-lactamases (ESBLs), which causes epidemiologic effect of $P$. mirabilis bacteremia (Sohn et al., 2011). The aim of the study is to Isolate and diagnose the bacteria $P$. mirablis isolated from patients with urinary tract infections and to identify the gene responsible for the production of virulence factor.

\section{Materials and Methods}

A total of 132 samples were collected from urine specimens or catheterized urine samples in sterile containers in different hospitals in Baghdad city (Al Kendy hospital, Al Yarmouk hospital, Medicine city/Baghdad teaching hospital, Central
Child hospital and Medicin city/Teaching labratory). During the period from $13 / 9 / 2015$ to $12 / 11 / 2015$. The samples were cultured on MacConkey agar and blood agar plates, and then incubated for 24 hours at $37 \circ \mathrm{C}$.

\section{Identification of isolates}

The isolates were identified depending on the morphological and biochemical tests and compared to the scheme described by Holt et al., (1994), then confirmed by the Api 20E test.

\section{Microscopic and Morphological Identification}

After the isolation of bacteria on MacConkey and blood agar, their shape, size, texture and colony arrangement were observed. Single colonies were picked up, stained with gram stain. Finally they were examined under microscope to identify their shape and length.

\section{Biochemical test}

Oxidase Test (Lanyi,1997); Indole test (Cruickshank et al., 1975); Blood Hemolysis Test (Collee et al., 1996); DNase and Urease test (Atlas et al., 1995).

\section{Antimicrobial susceptibility test}

Twelve antimicrobials discs were used to detect the sensitivity of 53 isolates of Proteus mirabilis according to Bauer et al., (1996) method. Bacterial isolates were cultured on MacConkey broth overnight a37॰C. Muller Hinton agar were prepared and distributed into petri dishes. Isolated colonies were suspended in $5 \mathrm{ml}$ normal saline, mixed by vortex. Their turbidity was compared against standard McFarland solution. Aliquot of $2 \mathrm{Ml}$ of bacterial 
suspension was placed on Muller Hinton plates, spread by cotton swab in three different directions by rotating the plate $60^{\circ}$ for each direction. The plate placed upside down for few minutes at room temperature. A number of antibiotics were placed on the plates and incubated at $37 \circ \mathrm{C}$ overnight. Inhibition zones were measured in $(\mathrm{mm})$ with zone inhibition ruler, the result compared to the National Committee for Clinical Laboratory Standards.

\section{Results and Discussion}

A total of 132 urine samples were collected from different hospitals in Baghdad city (33 from Medicine city/Central Child hospital,21 samples from the Medicine city/Baghdad teaching hospital, 19 from AlKindy,14 from Medicine city/Teaching laboratory and 11 from Al-Yarmouk hospital. The primary characterization of Gram negative bacteria depended on gram stain and their ability to ferment lactose on MacConkey agar, swarming on blood agar, as well as on oxidase and indole tests (Holt et al., 1994). The prevalence of bacterial isolates in different specimen showed that there was variation in causative agents. the major bacterium was E.coli with high occurrence frequency 59 followed by Proteus mirabilis in a percentage of 53, E.facalis 10, P.vulgaris 6 and Klebsiella species 4 , this result was almost similar to that of Caliskan, (2005) who indicated that the major bacterium was $E$. coli, followed by $P$. mirabilis, E. faecalis, P.vulgaris and K. pneumoniae. Figure(1).

\section{Isolation and identification of Proteus mirabilis}

Fifty Three isolates of Proteus mirabilis were characterized by cultural, microscopic diagnosis, biochemical testes, API 20E system and Vitek 2 system as a confirmatory techniques. The colony morphology of Proteus genus was initially identified according to their swarming phenomenon on blood agar, also they have a distinctive fish odor (Figure.2). While Proteus growth on MacConkey appeared to be pale due to incapability of this genus to ferment lactose sugar (O'hara et al., 2000).

\section{Biochemical tests}

Several biochemical tests were done for the identification of Proteus mirabilis. All the fifty three isolates showed positive results for urease, negative results for oxidase (Table 1), these results agreed with (Kishore, 2012; Kamga et al., 2012).

For further confirmation of Proteus mirabilis, API 20E test were done for the selected isolates, and the results agreed with the biochemical tests and reveled that these isolates were Proteus mirabilis table (2).

\section{Prevalence of Proteus mirabilis in the Urine samples}

The results indicated that Proteus species isolates among the total sample isolates were 59, and Proteus mirabilis was 53, whereas Proteus vulgaris was six (Figure 3). These results confirmed with that reported by Kadhimet al.,(2014) how mentioned that among the Proteus spp. isolates the percentage of Proteus mirabilis 12(85.7\%) was more than Proteus vulgaris two (14.3\%) from total Proteus isolates, this variation may be due to the differences in the size of sample, number of hospitals surveyed, and medication taken before sampling. Also Ismail, (2004) found that the isolation of 67 isolates of Proteus spp. from 598 samples of U.T.I. patients from different regions in Yemen and the diagnostic results indicated that 62 isolates (\% 92.54) were Proteus mirabilis while the remaining 5 isolates $(\%$ 
7.46) were Proteus vulgaris. Since Proteus mirabilis have many virulence factors that are vital for inflicting UTI, several of these factors appear to be more important for establishing infection in different areas of the urinary tract (Al-Bassam, 2010). Therefore Proteus species isolates percentage from the total number of urine isolates was 59, which was higher in comparable with other samples, and $P$. mirabilis was 53 table (1), figure (1), which was confirmed with that result of Wang et al., (2014), who found P. mirabilis isolates were $(49.4 \%)$ from the most isolates were collected from urine, as well as Singh et al., (2015) reported that 45 isolates belong to the Proteus species was collected from 100 sample of urine. On the other hand a recent study in Al-Diwanyia city produced by Ali and Yousif ( 2015) found that the Proteus mirabilis percentage was $(17.64 \%)$ in patient with urinary tract infection.

This result shows elevation in the infection by proteus spp. among UTI patients, because this species especially Proteus mirabilis is normally found in the human intestine along with other organisms composing a highly complex micro flora, they also inhabit other outside environments, and are especially prevalent in hospitals and care facilities, the skin and mucus of both patients and personnel working in these environments, which may be the primary vectors for pathogenicity, plus this bacteria metabolically involved in urease production which act as one of the reasons the pathogen is successful in colonizing the urinary tract and cause infection in humans (Kearns, 2010), furthermore motility of this isolate is highly complex, which is called swarming, is a primary factor in the success of Proteus mirabilis in causing complicated UTI and other more serious bladder and kidney infections.

In addition to their adaptive mobile abilities, other virulence factors have deemed Proteus mirabilis successful UTI causative agents. Overtime their inhabitance in hospitals has led to the expression of several antimicrobial resistance genes making infections very difficult to treat (Carey et al., 2013).

\section{Antimicrobial susceptibility of $P$.mirabilis}

Depending on NCCLs (2007) guideline, Fifty Three isolates were tested against twelve antimicrobials discs. Differences in the antimicrobials resistance were observed. Most of the isolates were resistant to Methicillin (95.6\%), and Rifampin (91.8\%). while the most effective drugs against $P$. mirabilis were Imipenem, Amikacin, Azetronam, Azithromycin and Ciprofloxacin.

Imipenem was the most effective drug against P.mirabilisisolates $(97.2 \%)$ was sensitive, Figure (4). This result was agreed with Shaaban et al., (2012), as well Yassen and Khelkal, (2015) were documented that the sensitivity of P.mirabilis is $100 \%$ to this antimicrobial. Some Proteus mirabilis isolates present an elevation in the resistance level to imipenem due to many reasons: the loss of outer membrane porins, decreased expression of PBP1a or reduced binding of imipenem by PBP2 (Girlich et al., 2014). Tsai et al., (2015) noted that the development of resistant against imipenem in Proteus mirabilis is due to the absence of $24 \mathrm{kDa}$ OMP.

Amikacin is an amino-glycoside antibiotic used to treat different types of bacterial infection. It is works by binding to the bacterial 30s ribosomal subunit, causing misreading of mRNA and leaving the bacterium unable to synthesize proteins vital to its growth. In this study P.mirabilis isolate show high sensitivity to amikacin (92.6\%), Figure (4). These result confirmed with result by Singla 
et al., 2015 found the percentage of susceptibility to amikacin was $87 \%$ to $98 \%$, which considered an agreement to this result.

In this study $P$. mirabili isolates showed high sensitivity against azetronam (81.7\%) Figure (4), these results were confirmed to that reported by Al-Bassam, 2010 who detected $(81 \%)$ sensitivity to this antimicrobial. Stock (2003) showed that P.mirabilis are naturally sensitive to azetronam, Whereas Yassen and Khelkal, (2015) reported an intermediate sensitivity.

In the presented study $(72.7 \%)$ of Proteus mirabilis isolates were sensitive to azithromycin see Figure (4), which agrees with a study in India by Manikandan and Amsath, (2013) showed $75 \%$ sensitivity to this antimicrobial in Proteus species isolates.

Ciprofloxacin is a synthetic chemotherapeutic antibiotic of the fluroquinolone drug class(Nelson et al, 2007), it is member of the broad spectrum antimicrobial agents, which inhibits bacterial DNA and protein synthesis and considered an important drug in the treatment of urinary tract infection. In this study (67.4\%) of the isolates were sensitive to Ciprofloxacin (Figure 4). A Study in Taiwan by Wang et al., (2014) reported that the susceptibility to this antimicrobial decreased (from $80.1 \%$ to $53.8 \%$ ), which is considered approximately in an agreement to the result of this study, about the development of resistant.

Gentamycin had a moderate activity on P.mirabilis isolates (55.8\%) see Figure (4), cause it belong to Aminoglycosides that are powerful broad spectrum antimicrobials, which are inhibitors of protein synthesis in prokaryote. A study in Taiwan by Wang et al. (2014) demonstrated that the rate of susceptibility to gentamicin was decreased to $(57.7 \%)$, which agrees with this study.

Tobramycin result showed $(56.5 \%)$ of the isolates were sensitive to this antimicrobial, Figure (4). A study by Alshwaikh et al., (2014) found the percentage of resistance was (40\%), which considered an agreement to this result, Whereas Patil. (2014) reported that the tobramycin was not able to inhibit the growth of proteus species more than $34 \%$.

Table.1 Biochemical test for P.mirabilis and P.vulgaris isolates from urine specimens collected from patients with acute UTI

\begin{tabular}{|c|c|c|}
\hline Biochemical test & P.mirabilis & P.vulgaris \\
\hline Oxidase & Negative & Negative \\
\hline Catalase & Positive & Positive \\
\hline Indole & Negative & Positive \\
\hline Vogas-Proskauer & Negative & Negative \\
\hline Urease & Positive & Positive \\
\hline Citrate Utilization & Positive & Positive \\
\hline Triple-Sugar Iron Agar & K/A++ & K/A++ \\
\hline Methyl Red & Positive & Positive \\
\hline
\end{tabular}


Table.2 Results of Api20 E diagnostic test for Proteus mirabilis

\begin{tabular}{|c|c|c|}
\hline Tests & Substrate & Proteus mirabilis \\
\hline ONPG & Ortho-nitrophenylGaactoside & - \\
\hline ADH & Arginine dehydrolase & - \\
\hline LDC & Lysine decarboxylase & - \\
\hline ODC & Ornithine decarboxylase & + \\
\hline CIT & Citrate & + \\
\hline H2S & Sodium Thiosulfate & + \\
\hline URE & Urea & + \\
\hline TDA & Tryptophan deaminase & + \\
\hline IND & Indol & - \\
\hline VP & Voges-proskauer & - \\
\hline GEL & Kohn's Gelatin & + \\
\hline GLU & Glucose & + \\
\hline MAN & Mannitol & - \\
\hline INO & Inositol & - \\
\hline SOR & Sorbitol & - \\
\hline RHA & Rhamnose & - \\
\hline SAC & Sucrose & - \\
\hline MEL & Melibiose & - \\
\hline AMY & Amygdalin & - \\
\hline ARA & Arabinose & - \\
\hline & & \\
\hline
\end{tabular}

Positive result(+) (-) Negative result

Fig.1 Number of bacterial isolates from urine sample.

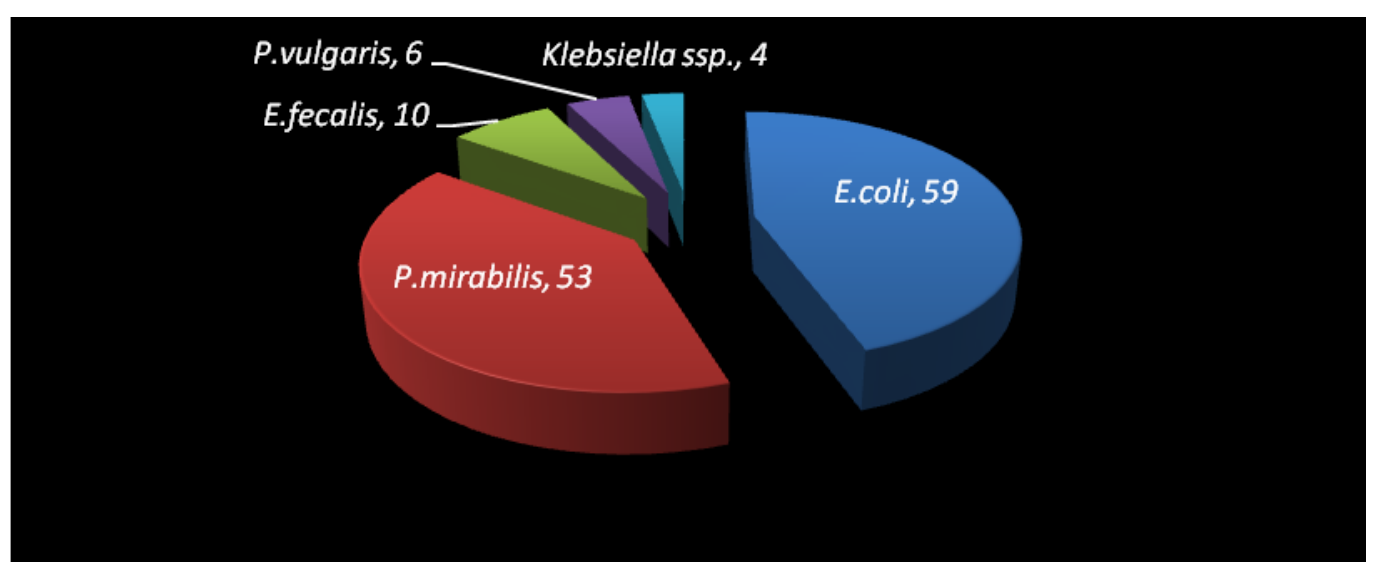


Fig.2 Proteus mirabilis on Blood agar

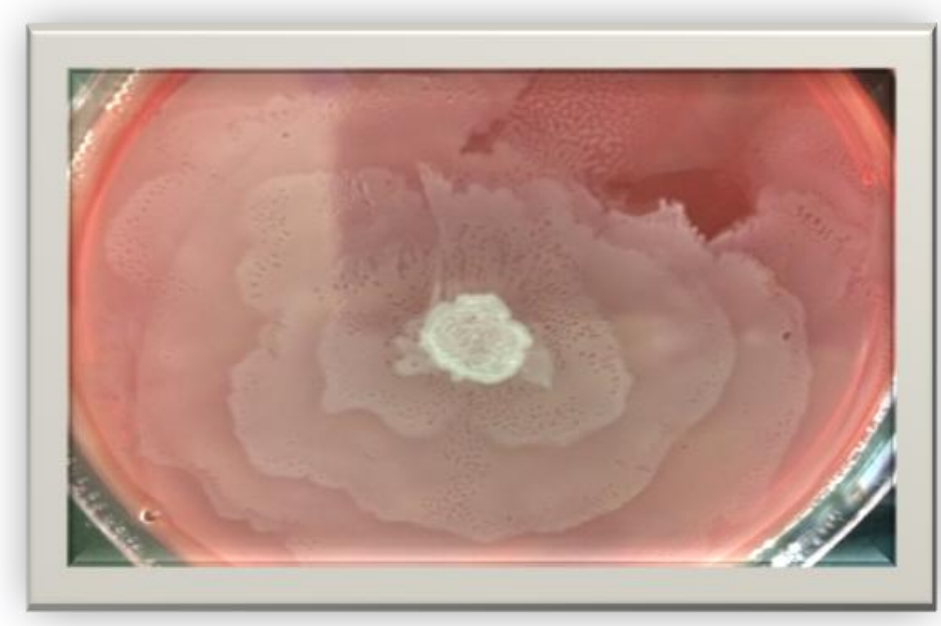

Fig.3 The percentage of P.mirabilis isolate and P.vulgaris isolated from patient suffering from UTI.

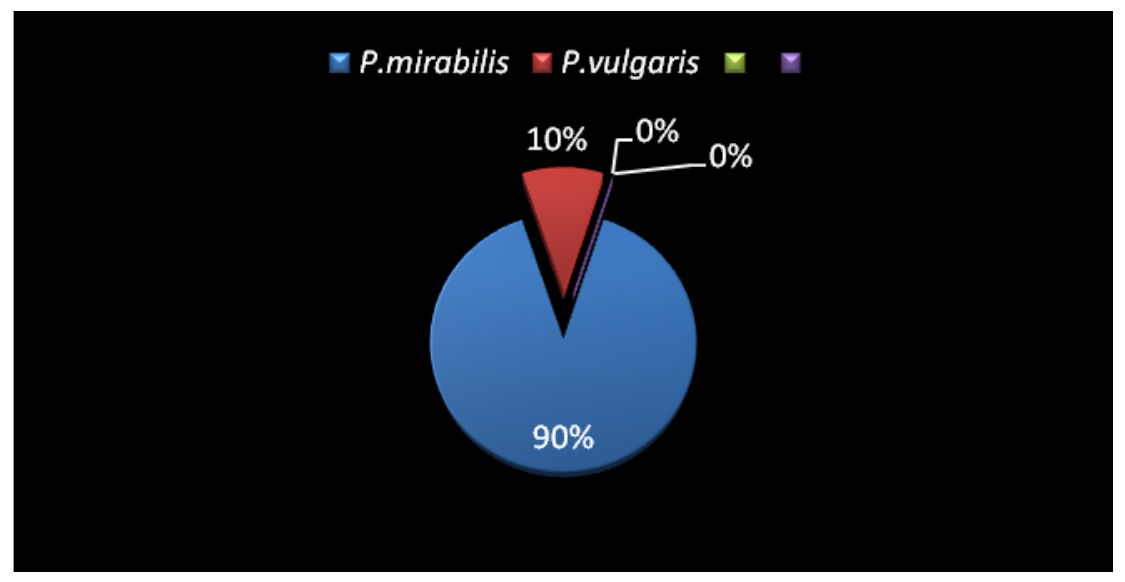

Fig.4 The antibiotic susceptibility test of P.mirabilis isolates.

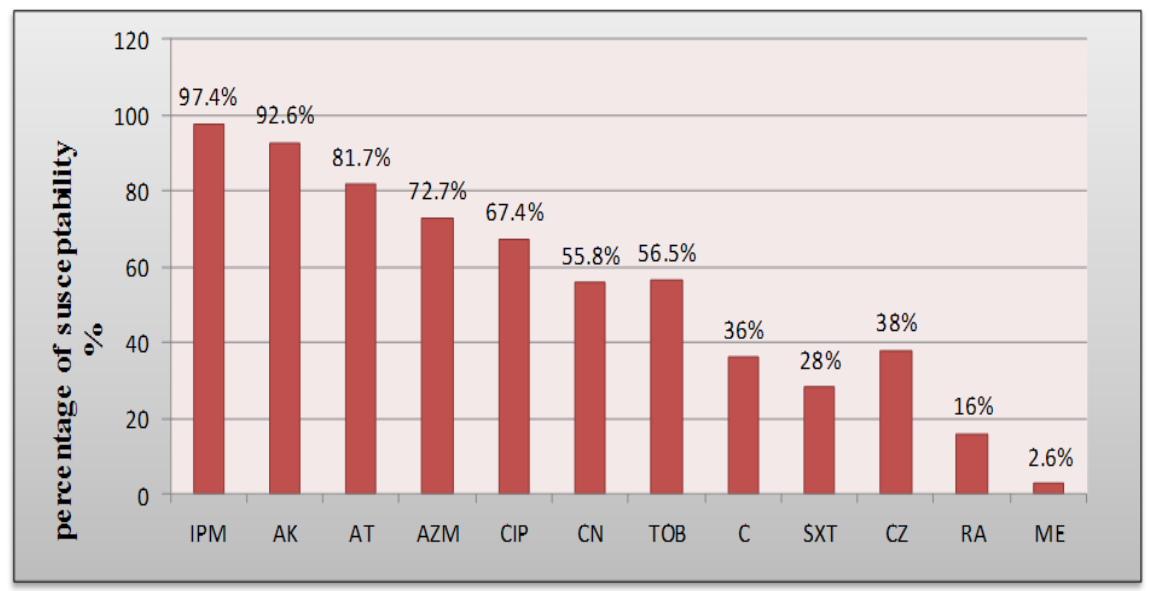


P.mirabilis showed (36\%) sensitivity to chloramphenicol in this study see (Figure 4), chloramphenicol is a bacteriostatic antimicrobial. It is a most common broadspectrum antibiotic, alongside the tetracycline. it is effective against a variety of Gram-negative and Gram-positive bacteria, including most anaerobic organisms. It prevents the peptidyl bond formation between the amino acids of growing polypeptide chain. Mordi and Momoh, (2009) demonstrated 28\% sensitivity of $P$. mirabilis that agree with this study.

Trimethoprim and sulfamethoxazole are combined together due to their synergism effect on bacteria. It's abroad spectrum bactericidal antimicrobial agent for both gram positive and gram negative bacteria. Trimethoprim is a diaminopyrimidine, whereas sulfamethoxazole is a sulfonamide and the Co-trimoxazole inhibits the synthesis of tetrahydrofolic acid, which is necessary for the synthesis of bacterial nucleic acid along with two components of the drug inhibiting different steps in the folate synthesis pathway (Ramlakhan et al., 2014). In this study $P$. mirabilis isolates developed high resistance $(72 \%)$ against trimethoprim-sulfamethoxazole see Figure (4), which was approximately confirmed with Nahar et al., (2014) reported a resistant percentage of $(66.7 \%)$.

Cefazolin, which is member of cephalosporin it is one of a drug that used for the treatment of $P$. mirabilis infection, but this study showed the pathogenic isolates appeared (62\%) resistance to cefazolin see Figure (4). Alkalifawi, (2015) documented that resistant $P$. mirabilis isolates about $(84 \%)$, this differentiation between both local studies may be due to the number of experimental urine samples, the type and site which were samples was taken, P.mirabilis show high resistant against
Rifampicin 94\% (Figure 4), Raghadaet al, (2013) reported that $P$. mirabilis isolates had moderate resistant against it, which disagreed with this result, whereas AlJawadi (2007) found that $P$. mirabilis isolates emerged $100 \%$ resistant to the same antimicrobial agent. Resistance of P.mirabilis against methicillin in a percentage $97.4 \%$ see Figure (4), this resistance may be due to increasing in the prevalence of plasmid-mediated extendedspectrum $\beta$-lactamases (ESBLs) in members of the family Enterobacteriaceae which has become a serious clinical problem on a worldwide scale(Nagano et al., 2003), on other hand them over use of this antimicrobial agent.

\section{References}

Al-Bassam, W. 2010. Bacteriological and genetic study on swarming in Proteus mirabilis isolated from clinical samples. (MSC thesis.University of Baghdad).

Ali, H.H. and Yousif, M.G. 2015. Detection of some virulence factors genes of Proteus mirablis that isolated from urinary tract infection. Int. J., 3(1): 156-163.

Al-Jebouri, M.M. and Mdish, S.A. 2013. Antibiotic resistance pattern of bacteria isolated from patients of urinary tract infections in Iraq. Open $J$. Urol., 3: 124-131.

AL-Kalifawi, E.J. 2015. Anti-Bacterial Activity of the Prophet Mohammad (SWS) Drink's against Pathogenic Bacteria. J. Natural Sci. Res., 5(4): 9098.

Alshwaikh, R.M.A., Al-Sorchee, S.M.A., Ali, K.A. and Al Beer, W. 2014. Antibacterial activity of parsley and celery aqueous extract on the isolated bacteria from children UTI in Erbil city. Int. J., 2(9): 895-903. 
Atlas, R.M., Parks, L.C. and Brown, A.E. 1995. Laboratory manual of experimental microbiology. MosbyYear Book, Missouri., 119-127.

Bauer, A.W., Kirby, W.M.M., Sherris, J.C. and Turck, M. 1996. Antibiotic susceptibility testing by a standardized single disk method. Am. J. Clin. Pathol., 45(4): 493-496.

Caliskan, Z. 2005. Studies on the epidemiology and pathogenesis of proteusmirabilis infections of the urinary tract in patients with urostomies (Doctoral dissertation, The Univ. of Wales College of Cardiff. (United Kingdom).

Carey, S., Copeland, M.F., Sacotte, R. tuson, H.H. and Weibel, D.B. 2013. Flagellum density regulates Proteus mirabilis swarmer cell motility in viscous environments. J. Bacteriol., 195(2): 368-377.

Chen, S.L., Jackson, S.L. and Boyko, E.J. 2009. Diabetes mellitus and urinary tract infection: epidemiology, pathogenesis and proposedstudies in animal models. J. Urol., 182(6): 5160.

Collee, J.G., Miles, R.S. and Watt, B. 1996. Tests for identification of bacteria. Mackie and McCartney practical medical microbiology. 14: 131-149.

Cruickshank, R., Duguid, J.P., Marmion, B.P. and Swain, R.H.A. 1975. Tests for identification of bacteria. Med. Microbiol., 12th ed. London: Churchill Livingstone., 170-189.

Elgozali, S.M., Al Fadhil, A.O. and Adam, A.A. 2015. Pyospermia and Bacteriospermia among Infertile Married Men attending Fertility Centers in Khartoum State, Sudan. American J. Res. Commu., 3(2): 4349.

Foxman, B. 2014. Urinary tract infection syndromes: occurrence, recurrence, bacteriology, risk factors, and disease burden. Infect. Dis. Clin. North America, vol. 28, pp.1-13.

Girlich, D., Dortet, L., Poirel, L. and Nordmann, P. 2014. Integration of the blaNDM-1 carbapenemase gene into Salmonella genomic island 1 (SGI1$\mathrm{W})$ in a Proteus mirabilis clinical isolate. J. Antimicrobial Chemother., dku371.

Holt, J.G., Krieg, N.R., Sneath, P.H.A., Staley, J.T. and Williams, S.T. 1994. Bergy's manual of determination bacteriology.9th ed. Williams and Wilkins, Baltimore, USA.

Ismail, S.M.A. 2004. Bacteriological and Biochemical study on urease from Proteus spp. Isolated from patients with urolthiasis in Yemen. Ph.D. Thesis, College of Science, AlMustansiriya University, Iraq.

Kadhim, A.F., AL-Mathkury, H.J. and Obaid, H.H. 2014. Role of Proteus mirabilis DNA in Comparison to Candida albicans DNA in Rats' Joints Infection. Iraqi J. Sci., 55(3B): 11701182.

Kamga, H.L.F., Nsagha, D.S., Assob, J.C.N., Njunda, A.L. and Tchape, G.N.E. 2012. Epidemiological studies on proteeae isolates from clinical specimens in the Laquintinie Hospital in Douala, Cameroon. African J. Clin. Experimental Microbiol., 13(2): 118126.

Kearns, D.B. 2010. A field guide to bacterial swarming motility. Nat. Rev. Microbiol., 8(9): 634-644.

Kishore, J. 2012. Isolation, identification \& characterization of Proteus penneri a missed rare pathogen. The Indian J. Med. Res., 135(3): 341- 345.

Lanyi, B. 1997. Classical and rapid identification methods for medically important bacteria. P 1-67.In Colwell, R.R. and Grigorova, R.(End). Methods 
in Microbiology.Vol. 19. Academic Press.Harcourt Brace Javanovih, Puplisher, London, New York.

Lauderdale, T.L.Y. 2014. Antimicrobial susceptibilities of Proteus mirabilis: a longitudinal nationwide study from the Taiwan surveillance of antimicrobial resistance (TSAR) program. BMC Infect. Dis., 14(1): 486.

Makled, A., and Alghamdi, A. 2006. Surveillance of Aminoglycosides Resistance Among Proteus mirabilis Isolates From Different Units in Jeddah Hospitals, Saudi Arabia. Egypt. J. Med. Microbiol., 15(2): 33.

Minardi, D. 2011. Urinary tract infections in women: etiology and treatment options. Int. J. Gen. Med., 4: 333-343.

Mordi, R.M. and Momoh, M.I. 2009. Incidence of Proteus species in wound infections and their sensitivity pattern in the university of Benin teaching hospital. Afr. J. Biotechnol., 8(5): 725730.

Nahar, A., Siddiquee, M., Nahar, S., Anwar, K.S. and Islam, S. 2014. Multidrug Resistant-Proteus Mirabilis Isolated from Chicken Droppings in Commercial Poultry Farms: Bio security Concern and Emerging Public Health Threat in Bangladesh. $J$. Biosafety Health Educ., 2(120): 23320893.

O'Hara, C., Brenner, F.W. and Miller, J.M. 2000. Classification, identification, and clinical significance of Proteus,
Providencia, and Morganella. Clin. Microbiol. Rev., 13: 534-546.

Ramlakhan, S., Singh, V., Stone, J. and Ramtahal, A. 2014. Clinical Options for the Treatment of Urinary Tract Infections in Children. Clin. Med. Insights Pediatr., 8: 31-37.

Singh, V., Kapoor, D. and Saini, P. 2015. Isolation of ESBL producing Proteus from UT patients. Int. J. Pharma. Res. Bio- Sci., 4(2): 91-97.

Singla, P., Sangwan, J., Garg, S. and Chaudhary, U. 2015. Prevalence and Antibiogram of Multidrug resistant Uropathogenic Isolates of Proteus mirabilis in a Teaching Tertiary Care Hospital. Int. J. Curr. Microbiol. App. Sci., 4(12): 675-682.

Sohn, K.M., Kang, C.I., Joo, E.J., Ha, Y.E., Chung, D.R., Peck, K.R., Lee, N.Y. and Song, J.H. 2011. Epidemiology of ciprofloxacin resistance and its relationship to extended-spectrum $\beta$ lactamase production in Proteus mirabilis bacteremia. The Korean $J$. Int. Med., 26(1): 89-93.

Stock, I. 2003. Natural antibiotic susceptibility of Proteus spp., with special reference to P.mirabilis and $P$. penneri strains. J. Chemother., 15(1): 12-26.

Wang, J.T., Chen, P.C., Chang, S.C., Shiau, Y.R., Wang, H.Y., Lai, J.F. and Yassen, L.T. and Khelkal, I.N. 2015. Effect of fatty acids on virulence factors of Proteus mirabilis. I.J.A.B.R., 5(2): 108-117.

\section{How to cite this article:}

Essam F.A. Al-Jumaily and Sara Hussein Zgaer. 2016. Multidrug Resistant Proteus mirabilis Isolated from Urinary Tract Infection from Different Hospitals in Baghdad City. Int.J.Curr.Microbiol.App.Sci. 5(9): 390-399. doi: http://dx.doi.org/10.20546/ijcmas.2016.509.042 